\title{
Clinical and economic studies of eptifibatide in coronary stenting
}

This article was published in the following Dove Press journal:

Therapeutics and Clinical Risk Management

2 August 2014

Number of times this article has been viewed

\section{Tilak Pasala \\ Prasongchai Sattayaprasert \\ Pradeep K Bhat \\ Ganesh Athappan \\ Sanjay Gandhi}

The Heart and Vascular Center, Case Western Reserve University/ MetroHealth, Cleveland, OH, USA

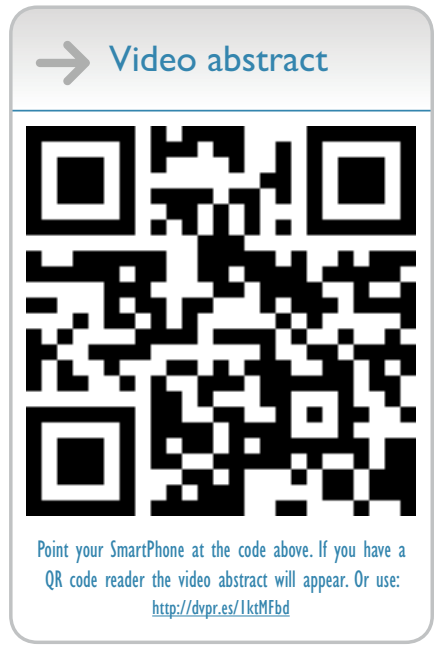

Correspondence: Sanjay Gandhi The Heart and Vascular Center, Case Western Reserve University/ MetroHealth, 2500 Metrohealth Drive, H330, Cleveland, OH 44109-1998, USA Tel +I 2167782357

Fax +I 2167783927

Email sgandhi@metrohealth.org
Abstract: Platelet adhesion and aggregation at the site of coronary stenting can have catastrophic clinical and economic consequences. Therefore, effective platelet inhibition is vital during and after percutaneous coronary intervention. Eptifibatide is an intravenous antiplatelet agent that blocks the final common pathway of platelet aggregation and thrombus formation by binding to glycoprotein IIb/IIIa receptors on the surface of platelets. In clinical studies, eptifibatide was associated with a significant reduction of mortality, myocardial infarction, or target vessel revascularization in patients with acute coronary syndrome undergoing percutaneous coronary intervention. However, recent trials conducted in the era of dual antiplatelet therapy and newer anticoagulants failed to demonstrate similar results. The previously seen favorable benefit of eptifibatide was mainly offset by the increased risk of bleeding. Current American College of Cardiology/American Heart Association guidelines recommend its use as an adjunct in high-risk patients who are undergoing percutaneous coronary intervention with traditional anticoagulants (heparin or enoxaparin), who are not otherwise at high risk of bleeding. In patients receiving bivalirudin (a newer safer anticoagulant), routine use of eptifibatide is discouraged except in select situations (eg, angiographic complications). Although older pharmacoeconomic studies favor eptifibatide, in the current era of $\mathrm{P} 2 \mathrm{Y}_{12}$ inhibitors and newer safer anticoagulants, the increased costs associated with bleeding make the routine use of eptifibatide an economically nonviable option. The cost-effectiveness of eptifibatide with the use of strategies that decrease the bleeding risk (eg, transradial access) is unknown. This review provides an overview of key clinical and economic studies of eptifibatide well into the current era of potent antiplatelet agents, novel safer anticoagulants, and contemporary percutaneous coronary intervention.

Keywords: eptifibatide, Integrilin ${ }^{\circledR}$, glycoprotein IIb/IIIa inhibitors, percutaneous coronary intervention, acute coronary syndrome, coronary artery disease, cost-effectiveness

\section{Introduction}

Compared with coronary angioplasty, percutaneous coronary intervention (PCI) with stenting remarkably improves survival in patients presenting with acute coronary syndrome (ACS). ${ }^{1}$ However, stenting causes platelet activation and aggregation that can lead to catastrophic thrombotic complications. ${ }^{2-4}$ Significant advances in stent technology and antiplatelet therapy have nevertheless reduced early ( 0 to 30 days) stent thrombosis to less than $1 \% .{ }^{5}$ Although stent thrombosis is infrequent in the modern era, it can be fatal (incidence of $20 \%-40 \%$ ) or, in those who survive, may result in increased need for revascularization. ${ }^{6}$ In addition to adversely impacting clinical outcomes, it imposes a significant financial burden on the health care system. In a retrospective study (3,295 stent procedures) the median total hospital cost to treat a stent thrombosis 
was $\$ 11,134$ per patient (2000 US dollars). ${ }^{7}$ In a study done on unselected elderly US Medicare patients undergoing PCI, for each patient who underwent repeat revascularization, one-year follow-up medical costs increased by $>\$ 19,000$ (2004 US dollars) per patient, even after adjustment for differences in baseline patient characteristics. ${ }^{8}$

The key role played by platelets in pathologic thrombosis forms the basis for using various antiplatelet agents in patients with ACS undergoing PCI. Aspirin, a thromboxane A2 inhibitor, when used alone has limited efficacy in preventing cardiovascular events after coronary stenting. ${ }^{9}$ This led to the development of potent antiplatelet agents that block different pathways in platelet activation and aggregation, such as glycoprotein (GP) IIb/IIIa inhibitors and $\mathrm{P} 2 \mathrm{Y}_{12}$ receptor blockers (Figure 1). Eptifibatide (Integrilin ${ }^{\circledR}$; ScheringPlough, Kenilworth, NJ, USA), is one of three intravenous GP IIb/IIIa inhibitors approved for use in the US market, the others being abciximab (ReoPro ${ }^{\circledR}$; Eli Lilly and Company, Indianapolis, IN, USA) and tirofiban (Aggrastat ${ }^{\circledR}$; Medicure Inc., Winnipeg, MB, Canada). Basic pharmacologic differences between eptifibatide and other intravenous GP IIb/IIIa inhibitors are summarized in Table $1 .{ }^{10,11}$ The current review evaluates in detail the clinical and economic impact of using eptifibatide as an antiplatelet agent in coronary stenting.

\section{Pharmacodynamic evaluation Biological properties}

Eptifibatide is a synthetic cyclic heptapeptide that contains a lysine-glycine-aspartic acid sequence and resembles hemotoxin in the venom of the southern pygmy rattlesnake. ${ }^{12}$ It is a reversible competitive antagonist that binds to the active site of GP IIb/IIIa receptor and prevents platelet aggregation. It prevents binding of fibrinogen, von Willebrand factor, and other adhesive ligands to GP IIb/IIIa receptors. In order to inhibit platelet aggregation effectively, $80 \%$ of GP IIb/IIIa function needs to be blocked. It has very high affinity for the GP IIb/IIIa receptor compared with abciximab and tirofiban, ${ }^{13}$ with a dissociation constant of $120 \mathrm{nM}$. It also has a rapid onset and short duration of action. Peak plasma concentration is reached in 5 minutes and it has a half-life of 2.5-2.8 hours. ${ }^{14}$ Maximum inhibition of platelet aggregation occurs in 15 minutes and inhibition returns to $50 \%$ of baseline at 4 hours after drug cessation. ${ }^{15}$ Eptifibatide and it's metabolites are primarily eliminated by the kidneys. The first step in metabolism is deamination, which makes a metabolite that was $41 \%$ of the platelet inhibitory effect of the primary compound. Therefore, a $50 \%$ dose reduction is recommended in patients with creatinine clearance less than $50 \mathrm{~mL}$ per minute, and eptifibatide is contraindicated in patients undergoing hemodialysis. ${ }^{10}$

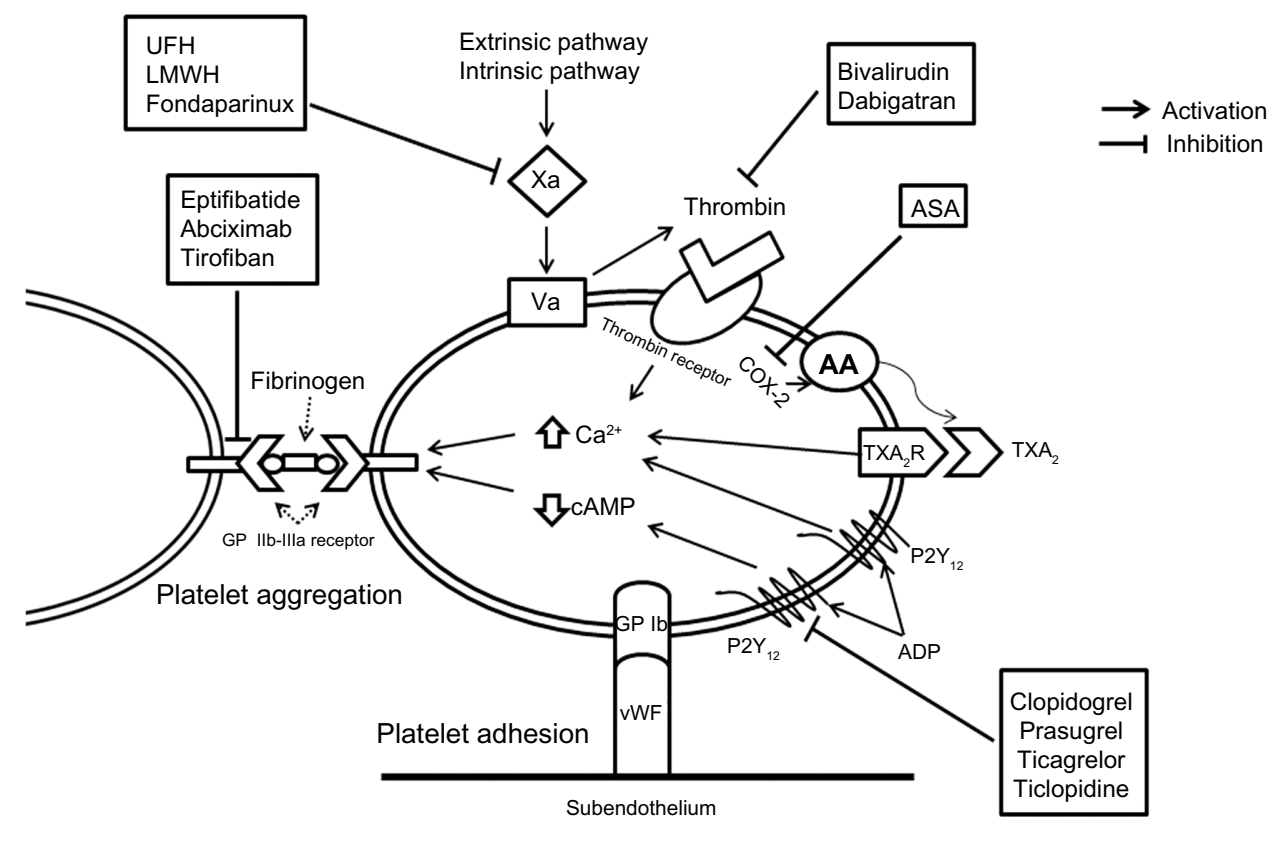

Figure I Platelet activation pathway and site of action of antiplatelet agents.

Notes: Platelets are activated via several different membrane receptors, resulting in platelet adhesion and aggregation. When endothelium is injured, the subendothelium exposes von Willebrand factor that binds to GP lb, causing platelet adhesion. Thrombin, TXA, and ADP bind to the thrombin receptor, TXA ${ }_{2}$ receptor, and P2Y ${ }_{12}$, respectively. This causes an increase in intracellular calcium $\left(\mathrm{Ca}^{2+}\right)$ and a decrease in cAMP, leading to platelet contraction and GP Ilb/Illa activation. Activated GP IIb/llla on adjacent platelets bind to fibrinogen (final common pathway) leading to platelet aggregation and thrombus formation.

Abbreviations: AA, arachidonic acid; COX-2, cyclo-oxygenase-2; cAMP, cyclic adenosine monophosphate; ADP, adenosine diphosphate; ASA, aspirin; UFH, unfractionated heparin; LMWH, low molecular weight heparin; TXA $A_{2}$, thromboxane $A_{2}$; GP, glycoprotein; vWF, von Willebrand factor; TXA $R$, thromboxane $A_{2}$ receptor. 
Table I Basic pharmacologic characteristics of glycoprotein Ilb/Illa inhibitors

\begin{tabular}{|c|c|c|c|}
\hline Characteristic & Eptifibatide & Abciximab & Tirofiban \\
\hline Type & $\begin{array}{l}\text { Synthetic cyclic } \\
\text { heptapeptide }\end{array}$ & $\begin{array}{l}\text { Fab fragment of } \\
\text { chimeric human- } \\
\text { murine monoclonal } \\
\text { antibody }\end{array}$ & $\begin{array}{l}\text { Synthetic } \\
\text { nonpeptide }\end{array}$ \\
\hline $\begin{array}{l}\text { Molecular } \\
\text { weight }\end{array}$ & $\begin{array}{l}\text { Small molecule } \\
(832 \mathrm{Da})\end{array}$ & $\begin{array}{l}\text { Large molecule } \\
(47,515 \mathrm{Da})\end{array}$ & $\begin{array}{l}\text { Small molecule } \\
(496 \mathrm{Da})\end{array}$ \\
\hline Plasma half-life & $2.5-2.8$ hours & $10-30$ minutes & I.2-2 hours \\
\hline $\begin{array}{l}\text { Receptor } \\
\text { binding }\end{array}$ & Seconds & Minutes & Seconds \\
\hline $\begin{array}{l}\text { Elimination } \\
\text { route }\end{array}$ & Renal $\sim 50 \%$ & Spleen & $\begin{array}{l}\text { Renal } 65 \% \\
\text { Biliary } 25 \%\end{array}$ \\
\hline
\end{tabular}

\section{Evolution of dosage regimen}

Eptifibatide is a small peptide that was approved by the US Food and Drug Administration in 1998. The first major clinical trial of eptifibatide, IMPACT-II (Integrilin to Minimize Platelet Aggregation and Coronary Thrombosis-II), did not show improvement in clinical outcomes due to use of a lower bolus dose $(135 \mu \mathrm{g} / \mathrm{kg}) .{ }^{16}$ The dose calculation was based on studies that overestimated inhibition of platelet aggregation. This occurred due to use of citrate-containing blood samples that lowered the calcium concentration. Calcium is needed for binding of fibrinogen to GP IIb/IIIa. ${ }^{17,18}$ Subsequently, in the PRIDE (Platelet aggregation and Receptor occupancy with Integrilin - a Dynamic Evaluation) trial, the protease inhibitor PPACK (D-phenylalanyl-L-prolyl-L-arginine chloromethyl ketone) was used in vitro for anticoagulation instead of citrate. This showed that a bolus dose of eptifibatide $180 \mu \mathrm{g} / \mathrm{kg}$ followed by infusion at a rate of $2 \mu \mathrm{g} / \mathrm{kg} / \mathrm{min}$ consistently achieved $>80 \%$ platelet aggregation inhibition. ${ }^{19}$

\section{Use in coronary stenting}

The evidence for clinical use of eptifibatide in coronary stenting is best discussed in the setting of the following scenarios.

\section{ST-segment elevation myocardial infarction}

Studies of eptifibatide in patients with ST-segment elevation myocardial infarction (STEMI) undergoing PCI are summarized in Table 2.

\section{Prior to use of $\mathrm{P} 2 \mathrm{Y}_{12}$ receptor inhibitors}

Large randomized controlled trials addressing the clinical outcomes of using eptifibatide as adjunctive therapy prior to the use of $\mathrm{P} 2 \mathrm{Y}_{12}$ receptor inhibitors (clopidogrel, prasugrel, and ticagrelor) are lacking. In two small trials, ie, INTAMI (Integrilin in Acute Myocardial Infarction) and TITAN (Time to Integrilin Therapy in Acute Myocardial
Infarction)-TIMI 34, early use of eptifibatide was associated with pre-PCI vessel patency but no significant difference in the rates of death, reinfarction, or stroke. ${ }^{20,21}$ However, neither trial was adequately powered to evaluate the relationship between administration of eptifibatide and clinical outcomes.

In the era of $\mathrm{P} 2 \mathrm{Y}_{12}$ receptor inhibitors

Upfront loading with a high-dose $\mathrm{P}_{2} \mathrm{Y}_{12}$ receptor inhibitor became common practice in patients undergoing PCI. Subsequently, the incremental benefit of addition of GP IIb/IIIa inhibitors came under scrutiny. In ASSIST (A Safety and Efficacy Study of Integrilin-Facilitated PCI in ST Elevation Myocardial Infarction), after administration of dual antiplatelet therapy, patients were randomized to PCI with heparin plus eptifibatide or to PCI with heparin alone. Open-label eptifibatide was given as two boluses of $180 \mu \mathrm{g} / \mathrm{kg}$ followed by a continuous infusion of $2.0 \mu \mathrm{g} / \mathrm{kg} / \mathrm{min}(1.0 \mu \mathrm{g} / \mathrm{kg} / \mathrm{min}$ if glomerular filtration rate was $<50 \mathrm{~mL}$ per minute) for 18 hours after PCI. No improvement in clinical outcomes was noted with eptifibatide plus heparin compared with heparin alone $(6.47 \%$ versus $5.53 \%$, respectively; $95 \%$ confidence interval $0.52-2.70) .{ }^{22}$

In the era of newer anticoagulants

Subsequent to introduction of bivalirudin, a direct thrombin inhibitor that was shown to be safer than heparin plus GP IIb/IIIa inhibitors for PCI, the planned usage of GP IIb/IIIa inhibitors declined because of concern about increased bleeding complications. In the landmark HORIZONS-AMI (Harmonizing Outcomes With Revascularization and Stents in Acute Myocardial Infarction) trial, ${ }^{23}$ anticoagulation using bivalirudin alone with provisional use of GP IIb/IIIa inhibitors $(7 \%)$ was compared with heparin plus planned GP IIb/ IIIa inhibitors (eptifibatide 46\%). GP IIb/IIIa inhibitors were provisionally used for angiographic findings of no reflow or giant thrombus after PCI in the bivalirudin group. There was no significant difference in the composite endpoint of death, reinfarction, target vessel revascularization, or stroke at 30 days $(5.4 \%$ versus $5.5 \%, P=0.95)$ or at one year $(11.9 \%$ versus $11.9 \%, P=0.98) .{ }^{24}$ However, there was a reduction in major bleeding $(4.9 \%$ versus $8.3 \%, P<0.001)$ in the bivalirudin group. The role of eptifibatide in primary PCI was subsequently reduced to provisional use, covered in detail in the Conclusion and place in therapy subsection.

\section{Unstable angina/NSTEMI and stable coronary artery disease}

Studies with eptifibatide in patients with unstable angina, non ST-segment elevation myocardial infarction (NSTEMI) or stable coronary artery disease undergoing PCI are summarized in Table 3. 


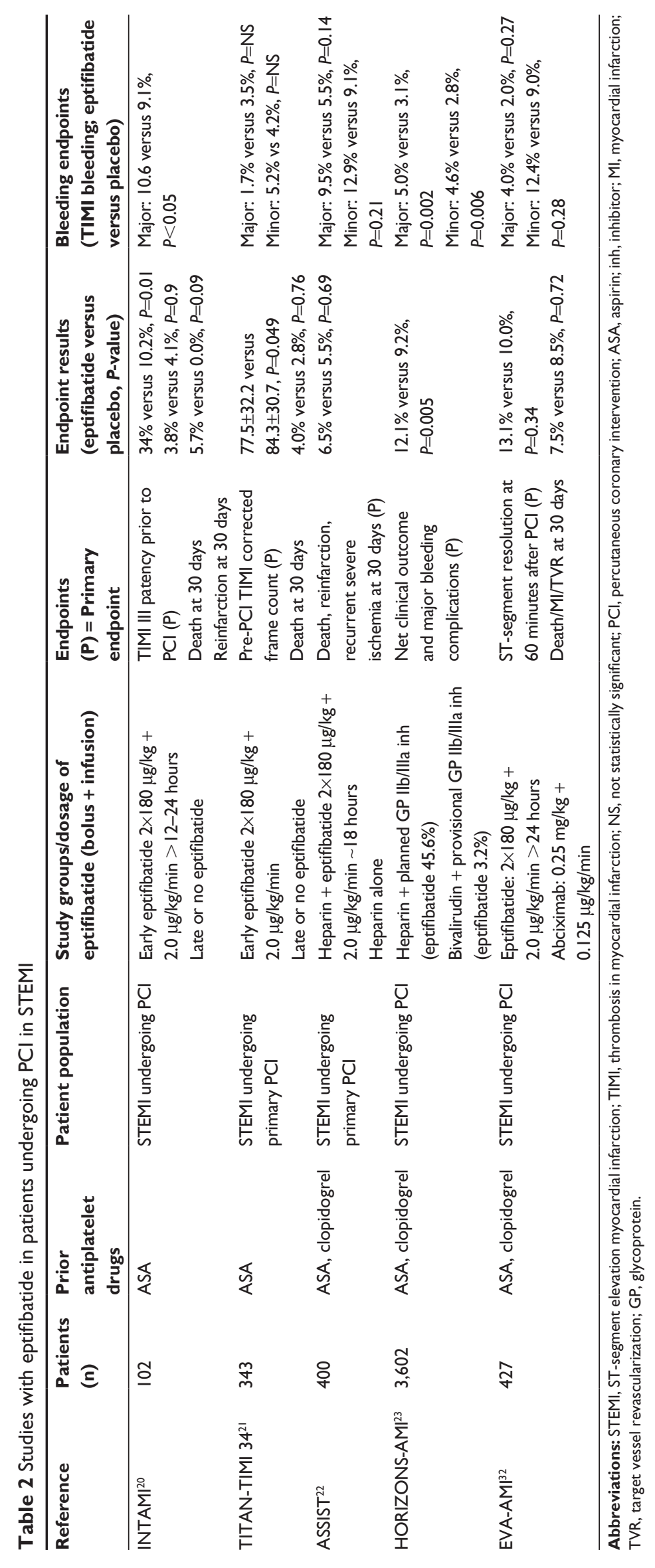




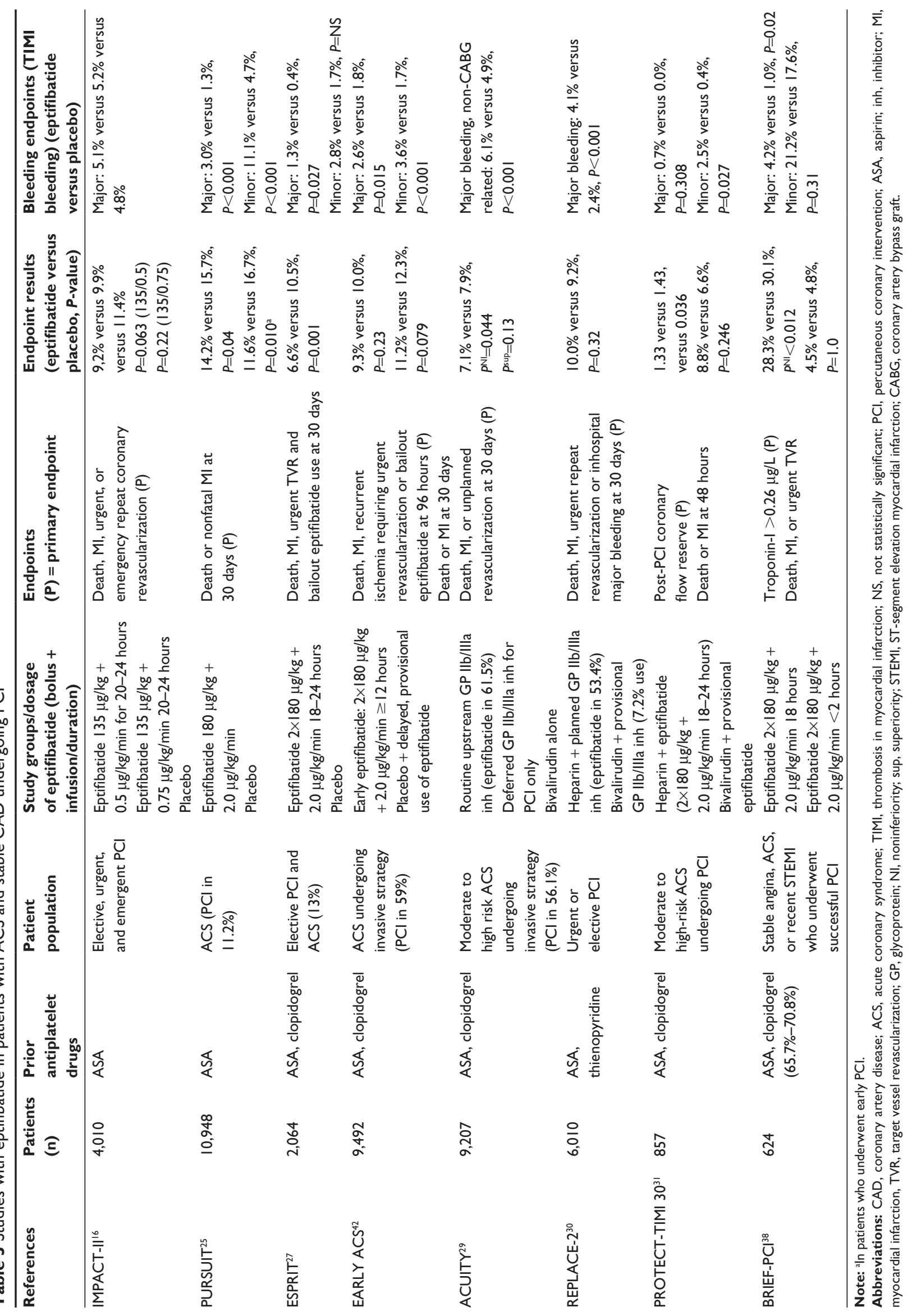




\section{Prior to use of $\mathrm{P}_{2} \mathrm{Y}_{12}$ receptor inhibitors}

Prior to routine use of $\mathrm{P}_{2} \mathrm{Y}_{12}$ receptor inhibitors, eptifibatide was studied in several randomized controlled trials. In the IMPACT-II trial ${ }^{16}(\mathrm{n}=4,010)$, patients undergoing elective, urgent, or emergent PCI were given a lower bolus dose $(135 \mu \mathrm{g} / \mathrm{kg})$ followed by two different infusion rates $(0.5 \mu \mathrm{g} / \mathrm{kg} / \mathrm{min}$ or $0.75 \mu \mathrm{g} / \mathrm{kg} / \mathrm{min})$. At 30 days, the primary endpoint (death, myocardial infarction, or urgent revascularization) was reduced by an eptifibatide infusion of $0.5 \mu \mathrm{g} / \mathrm{kg} / \mathrm{min}$ compared with placebo $(9.1 \%$ versus $11.6 \%$, $P=0.035$ ), with no significant difference seen at the higher infusion dose. These doses were felt to be at the lower end of the efficacy response curve. Hence, subsequent studies used a higher bolus dose of eptifibatide $180 \mu \mathrm{g} / \mathrm{kg}$. In the PURSUIT (Platelet Glycoprotein IIb/IIIa in Unstable Angina: Receptor Suppression Using Integrilin Therapy) trial, ${ }^{25}$ eptifibatide (a single bolus of $180 \mu \mathrm{g} / \mathrm{kg}$ ) significantly reduced death and nonfatal myocardial infarction ( $14.2 \%$ versus $15.7 \%, P=0.04$ ) at 30 days compared with placebo. The benefit was more pronounced in patients who underwent early PCI $(11.6 \%$ versus $16.7 \%, P=0.010) .{ }^{26}$ However, use of eptifibatide was associated with a higher incidence of bleeding and frequent blood transfusions.

\section{In the era of $\mathrm{P}_{2} \mathrm{Y}_{12}$ receptor inhibitors}

In the ESPRIT (Enhanced Suppression of the Platelet IIb/IIIa Receptor with Integrilin Therapy) trial, high-risk patients (age $>75$ years, with diabetes, elevated cardiac markers, STEMI within 7 days, or unstable angina within 48 hours of randomization) received a double dose of eptifibatide or placebo in a randomized, double-blind fashion prior to initiation of PCI. Both groups were pretreated with aspirin and a thienopyridine (either ticlopidine or clopidogrel). The primary endpoint (composite of death, myocardial infarction, urgent target vessel revascularization, and thrombotic bailout GP IIb/IIIa inhibitors within 48 hours after randomization) was reduced from $10.5 \%$ to $6.6 \%(P=0.0015)$ by eptifibatide when compared with placebo. The secondary endpoint of death, myocardial infarction, and urgent target vessel revascularization at 30 days was reduced from $10.5 \%$ to $6.8 \%$ $(P=0.0034)$. Major bleeding was infrequent, but seen more often with eptifibatide ( $1.3 \%$ versus $0.4 \%, P=0.027) .27,28$

\section{In the era of newer anticoagulants}

In the ACUITY (Acute Catheterization and Urgent Intervention Triage strategY) trial, 9,207 moderate to high-risk ACS patients were randomized to unfractionated heparin plus a GP IIb/ IIIa inhibitor versus bivalirudin plus a GP IIb/IIIa inhibitor versus bivalirudin alone. In the subgroup analysis of patients undergoing PCI, addition of a GP IIb/IIIa inhibitor (eptifibatide use $=60 \%$ ) to heparin did not improve the composite ischemic outcome ( $8 \%$ versus $9 \%, P=0.45$ ) but significantly increased major bleeding ( $7 \%$ versus $4 \%, P<0.0001$ ) when compared with bivalirudin alone. ${ }^{29}$ Similar results were seen in the REPLACE (Randomized Evaluation in PCI Linking Angiomax to Reduced Clinical Events)-2 trial, ${ }^{30}$ in which heparin plus planned GPI IIb/IIIa inhibitors (53.4\% received eptifibatide) during PCI was no different to bivalirudin plus provisional use (7.2\%) of GP IIb/IIIa inhibitors with regard to the acute ischemic endpoint ( $10 \%$ versus $9.2 \%, P=0.32$ ) but was associated with increased bleeding (4.1\% versus $2.4 \%$, $P<0.001$ ). In the PROTECT (Randomized Trial to Evaluate the Relative PROTECTion against Post-PCI Microvascular Dysfunction and Post-PCI Ischemia among Anti-Platelet and Anti-Thrombotic Agents)-TIMI 30 trial, ${ }^{31} 857$ patients with moderate to high-risk ACS undergoing PCI were randomized to heparin plus planned eptifibatide versus bivalirudin plus provisional eptifibatide. The primary endpoint of post-PCI coronary flow reserve was higher in the bivalirudin group (1.43 versus $1.33, P=0.036$ ) with no significant difference in death or myocardial infarction at 48 hours. Although no difference in incidence of major REPLACE-2-type bleeding was seen, the incidence of minor bleeding was higher in the heparin plus eptifibatide group. Thus, eptifibatide plus heparin is no different in efficacy to bivalirudin, but is associated with a higher risk of bleeding.

\section{Eptifibatide versus other GP Ilb/llla inhibitors}

Differences in cardiovascular outcomes were noted between the different GP IIb/IIIa inhibitors; however, evidence to suggest the superiority of eptifibatide over other GP IIb/IIIa inhibitors or vice versa is lacking. In the EVAAMI (Eptifibatide Versus Abciximab in Primary PCI for Acute Myocardial Infarction) trial, ${ }^{32}$ which had a noninferiority design and enrolled 427 patients undergoing primary PCI, eptifibatide was as effective and safe as abciximab with respect to myocardial perfusion and clinical events. In the Swedish Coronary Angiography and Angioplasty Registry, comparison of STEMI patients undergoing primary PCI receiving either eptifibatide or abciximab $(n=11,479)$ was done with a prespecified noninferiority margin set at 1.29. Eptifibatide was shown to be noninferior to abciximab with respect to death or myocardial infarction at one year (odds ratio $0.94,95 \%$ confidence interval $0.82-1.09) .{ }^{33}$ In a subset analysis of the HORIZONS-AMI trial using propensity score 
matching, there was no statistically significant difference between abciximab and eptifibatide for major bleeding risk (hazard ratio $1.05,95 \%$ confidence interval $0.78-1.41$ ) or clinical efficacy (hazard ratio $0.96,95 \%$ confidence interval $0.77-1.20)$ at 3 years. ${ }^{34}$

\section{Bleeding risk and approaches to improve safety}

The bleeding risk with GP IIb/IIIa inhibitors is increased in women, older patients, and in those with renal deficiency. ${ }^{35-37}$ In patients with creatinine clearance $\leq 50 \mathrm{~mL}$ per minute, eptifibatide is recommended as a $180 \mu \mathrm{g} / \mathrm{kg}$ bolus administered immediately before initiation of PCI followed by a lower infusion rate of $1 \mu \mathrm{g} / \mathrm{kg} / \mathrm{min}$. A second $180 \mu \mathrm{g} / \mathrm{kg}$ bolus 10 minutes after the first bolus can be given. Eptifibatide is contraindicated in patients on hemodialysis.

\section{Bolus only/short infusion versus long infusion}

Currently eptifibatide is given as a continuous infusion for 18-24 hours after PCI. A new dose regimen of eptifibatide was explored in the BRIEF-PCI (Brief Infusion of Intravenous Eptifibatide Following Successful Percutaneous Coronary Intervention) trial, ${ }^{38}$ where a single bolus dose plus a truncated infusion ( $<2$ hours) of eptifibatide was used in low-risk patients undergoing PCI and was found to have a similar incidence of death, myocardial infarction, and target vessel revascularization (not statistically significant), but with less incidence of major bleeding ( $1.0 \%$ versus $4.2 \%, P=0.02$ ). This trial showed that after a successful and uncomplicated PCI, the value of prolonged infusion is limited, especially in low-risk patients. Similar findings were noted in a retrospective study by Kini et al, ${ }^{39}$ where 2,629 patients who received either a GP IIb/IIIa inhibitor (72\% eptifibatide) bolus plus infusion versus a GP IIb/IIIa inhibitor bolus only were compared. Patients receiving the bolus only had similar periprocedural and one-year ischemic outcomes, but with reduced vascular bleeding events compared with the bolus plus infusion. Additionally, bolus only increased ambulatory PCI and reduced the length of stay. One could speculate that there may be a role for eptifibatide with bolus only/truncated infusion in the bivalirudin era. This could be substantiated by the argument that despite thienopyridine pretreatment, a large proportion of patients do not have optimal platelet inhibition during PCI. ${ }^{40,41}$ However, the above studies included low-risk patients, and there is a need for larger trials exploring this dosage regimen in high-risk patients, in whom GP IIb/IIIa inhibitor use is most beneficial.

\section{Routine upstream versus delayed selective use}

The optimal timing of administration of eptifibatide was unclear. Whether upstream versus deferred/or delayed (at the time of PCI) had an effect on outcomes was explored in a few randomized controlled trials. In the EARLY ACS trial (ClinicalTrials.gov identifier NCT00089895), ${ }^{42}$ 9,492 patients with high-risk ACS undergoing an invasive strategy (59\% underwent PCI) were studied to determine if routine early eptifibatide use was superior to provisional delayed use at the time of PCI. Eptifibatide infusion was given for 18-24 hours after PCI in both groups. No significant difference in the primary endpoint was noted between the early eptifibatide group and the delayed eptifibatide group (9.3\% versus $10.0 \%$, respectively, $P=0.23$ ). However, patients in the early eptifibatide group had significantly higher TIMI major (2.6\% versus $1.8 \%, P=0.015)$ and minor $(3.6 \%$ versus $1.7 \%, P<0.001)$ bleeding. In the ACUITY trial, ${ }^{43}$ patients on GP IIb/IIIa inhibitor therapy $(61.5 \%$ of patients of the routine upstream group received eptifibatide) were further randomized to routine upstream versus deferred selective use. There was no significant difference in the rate of the composite endpoint of death, myocardial infarction, or unplanned revascularization for ischemia between routine upstream use compared with deferred selective use of a GP IIb/IIIa inhibitor $(7.1 \%$ versus $7.9 \% ; P=0.044$ for noninferiority, $P=0.13$ for superiority). However, deferred therapy was associated with significantly less major bleeding at 30 days $(4.9 \%$ versus $6.1 \%, P<0.001)$. Thus, in patients pretreated with $\mathrm{P}_{2} \mathrm{Y}_{12}$ inhibitors, upstream use of eptifibatide is associated with increased bleeding risk and should be avoided.

\section{Radial versus femoral access}

Radial access may obviate the bleeding risk associated with GP IIb/IIIa inhibitors. In a subgroup analysis of the ACUITY trial, the advantage of reduction of major bleeding seen with bivalirudin monotherapy over heparin plus GP IIb/IIIa inhibitors (eptifibatide 60\%) was no longer significant when radial access was used $(4.2 \%$ versus $2.2 \%, P=0.19) .{ }^{44}$ In a single-center, prospective, registry study performed in the $\mathrm{UK},{ }^{45}$ consecutive patients undergoing primary PCI with unfractionated heparin plus eptifibatide via radial access were enrolled and compared with the bivalirudin arm of the HORIZONS-AMI trial. In the subgroup of patients fulfilling the HORIZONS-AMI entry criteria, major bleeding was no different to that in the bivalirudin arm of HORIZONS-AMI ( $3.7 \%$ versus $4.9 \%, P=0.32$ ). This observation is noteworthy because the registry consisted of patients with a high bleeding 
risk and unselected STEMI, who were pretreated with a thienopyridine prior to primary PCI. A Canadian study ${ }^{46}$ that propensity-matched 3,198 patients undergoing PCI via radial access to 3,198 patients undergoing PCI via femoral access ( $80 \%$ unfractionated heparin with eptifibatide use in both groups) showed that radial access was an independent predictor of fewer access site complications (odds ratio $0.39,95 \%$ confidence interval $0.2-0.7$ ). Thus, further studies comparing unfractionated heparin plus eptifibatide with newer anticoagulants in patients undergoing PCI via radial access may be warranted.

\section{Pharmacoeconomic evaluation}

Cost-effectiveness data for routine addition of eptifibatide to unfractionated heparin coming from evaluation of larger randomized controlled trials may not necessarily reflect "real-world" costs. In a prospective economic study ${ }^{47}$ of patients enrolled in the PURSUIT trial, the incremental cost-effectiveness ratio for routine addition of eptifibatide to unfractionated heparin in the US cohort of PURSUIT patients was $\$ 16,491$ (1996 US dollars) per year of life saved, and the cost-utility ratio for eptifibatide was $\$ 19,693$ per added quality-adjusted life-year. Eptifibatide was felt to be economically attractive for usual care of NSTEMI by conventional standards. In an economic analysis ${ }^{48}$ of the ESPRIT trial (US cohort), the acquisition cost of eptifibatide was offset by reduced medical resource consumption during the initial hospitalization period (by 40\%) and over a one-year period (by 70\%). In the real-world retrospective analysis, similar results with eptifibatide were seen. In a retrospective US cost-effectiveness analysis that incorporated data from the ESPRIT trial and modeled life expectancy using a large cardiovascular database, eptifibatide was associated with a favorable cost-effectiveness ratio of \$1,407 (2000 US dollars) per life-year gained. The cost-effectiveness of adding eptifibatide to unfractionated heparin for selected high-risk patients undergoing PCI in Germany was studied by Dewilde et al. ${ }^{49}$ They showed that while eptifibatide was an additional expense initially, it recovers its cost by avoiding costly repeat procedures and preventing cardiovascular events, leading to positive quality-adjusted life-year gains. The incremental net benefit of its use exceeded $€ 10,000$ (about $\$ 13,000$ in 2006 US dollars) from a hospital and a third-party payer perspective.

Among the GP IIb/IIIa inhibitors, eptifibatide was seen to be more economically attractive. The PRICE (Prairie ReoPro versus Integrilin Cost Evaluation) trial ${ }^{50}$ compared the overall hospital costs of eptifibatide and abciximab in patients undergoing elective PCI. While inhospital and 30-day composite outcomes (death, nonfatal myocardial infarction, and urgent revascularization) were similar (5.6\% versus $6.3 \%, P=0.95)$, the median inhospital cost (1999/2000 US dollars) with eptifibatide ( $\$ 7,207$, interquartile range $\$ 5,659$, $\$ 9,307)$ was lower than with abciximab $(\$ 8,268$, interquartile range $\$ 6,505, \$ 9,958)$. This difference was sustained even at 30 days. In a retrospective cohort analyses of outcomes and costs between abciximab and eptifibatide, comparable outcomes for safety and effectiveness were seen, but the total costs for hospitalization $(\$ 16,383 \pm 6,799$ versus $\$ 14,115 \pm 6,285, P<0.001)$ and drug acquisition costs ( $\$ 508 \pm 159$ versus $\$ 465 \pm 263, P=0.003$ ) were greater for abciximab than for eptifibatide. ${ }^{51}$ In a review of published data from 1994 to 2002 in the setting of PCI, Le Pen et al ${ }^{52}$ noted that eptifibatide had lower acquisition and treatment costs compared with abciximab. However, if cost was weighted by clinical trials, the difference disappeared or even reversed. They concluded that the concept of cost, inevitably entering into the choice of a medical strategy, must be used with caution. The cost implications in TRANSFER-AMI (Trial of Routine ANgioplasty and Stenting after Fibrinolysis to Enhance Reperfusion in Acute Myocardial Infarction) ${ }^{53}$ were studied by Bagai et al. ${ }^{54}$ The TRANSFER-AMI trial randomized 1,059 high-risk patients with STEMI to routine early PCI or PCI only for failed fibrinolysis. There was high and similar usage of GP IIb/IIIa inhibitors in both groups ( $83.6 \%$ versus $81.2 \%, P=0.39$ ). At one year, there was no difference in death or reinfarction $(10.3 \%$ versus $11.6 \%$, $P=0.50)$. In the cost analysis, the routine early PCI group had a higher cost (2008 US dollars) per patient (difference \$1,003, $95 \%$ confidence interval $-247,2,211$ ) and this was driven mainly by air transportation and higher use of abciximab than eptifibatide (2:1 compared with 4:5 in PCI only for failed fibrinolysis). Further analysis showed that if eptifibatide was used primarily, drug costs would be lower by $\$ 300$ per patient, reducing the overall difference in study costs between routine early PCI and PCI only for failed fibrinolysis from $\$ 1,003$ to $\$ 629$. Additionally, in a scenario where land-only transportation and use of eptifibatide was taken, difference in costs between routine early PCI and PCI only for failed fibrinolysis reduced from $\$ 1,003$ to as low as $\$ 108$.

With the advent of bivalirudin alone as an option for anticoagulation after PCI, routine addition of eptifibatide to unfractionated heparin was not economically viable due to higher acquisition costs and costs related to bleeding complications. Economic evaluation of the REPLACE- 2 trial $^{55}$ showed that routine eptifibatide plus unfractionated heparin 
increased inhospital and 30-day costs (2002 US dollars) by $\$ 405$ and $\$ 374$, respectively. In a cost-effectiveness analysis of the REPLACE- 2 trial and three other randomized controlled trials ${ }^{56}$ bivalirudin with provisional GP IIb/IIIa inhibitors was shown to be more cost-effective than unfractionated heparin with planned GP IIb/IIIa inhibitors. However, sensitivity analyses revealed that unfractionated heparin with eptifibatide was more cost-effective if two or more vials of bivalirudin were used ( $27 \%$ of the cases) or provisional use of GP IIb/ IIIa inhibitors exceeded $20 \%$. Additionally, unfractionated heparin with eptifibatide was better than abciximab (\$74 more expensive and $1.2 \%$ less effective versus $\$ 777$ more expensive and $2.3 \%$ less effective). Among US patients in the ACUITY trial, unfractionated heparin plus a GP IIb/IIIa inhibitor during PCI was associated with $\$ 200$ (2005 US dollars) lower initial hospital stay net cost savings compared with bivalirudin alone. ${ }^{57}$ This was primarily due to more major and minor bleeding associated with GP IIb/IIIa inhibitors. A higher baseline risk of bleeding confers a higher absolute benefit of any therapy associated with a fixed relative risk reduction of bleeding as seen with bivalirudin. ${ }^{58}$ Therefore, the favorable cost-effectiveness seen with bivalirudin in the above trials and other studies ${ }^{59}$ might be overestimated given that routine use of eptifibatide has declined in the real world, along with the associated bleeding risk. In addition, potential adaptation of further strategies, such as radial access PCI that reduces the bleeding risk, may further decrease the cost difference.

The efficacy, safety, and cost of high-dose $(20 \mathrm{mg})$ single bolus eptifibatide was studied by Fischell et a ${ }^{60}$ as an alternative to a conventional double bolus plus intravenous infusion regimen during elective PCI. The primary endpoint was similar to that of the ESPRIT and REPLACE-2 trials, and the average per patient cost of anticoagulation was $\$ 66$. In perspective, the respective costs of eptifibatide and bivalirudin were $\$ 930$ and $\$ 530$ (2006 US dollars) in the REPLACE-2 trial. ${ }^{56}$ However, this was an observational registry study without a control arm and the patients were not a high-risk ACS group where the benefit of a GP IIb/IIIa inhibitor is greatest. ${ }^{61}$ More studies of the efficacy and cost-effectiveness of this dosing regimen should be done in the future.

\section{Conclusion and place in therapy}

Antiplatelet therapy in patients undergoing PCI for ACS has been shown to reduce major adverse cardiovascular events. ${ }^{62}$ Aggressive platelet inhibition can be achieved by eptifibatide, which differs in its pharmacologic properties from other GP IIb/IIIa inhibitors. While no large randomized controlled trials were done to compare eptifibatide with other agents, equivalent efficacy was seen in indirect analyses. The role of eptifibatide in the contemporary era, where pretreatment with dual antiplatelet therapy and use of newer safer anticoagulants (especially bivalirudin) at the time of PCI is routine practice, has become more refined and can be best elucidated in select clinical situations (Table 4) ${ }^{63-65}$ Major bleeding has limited the widespread use of eptifibatide as the net benefit fades away in low-risk patients undergoing stenting.

In patients with STEMI undergoing PCI, there is evidence for early use, if not pretreated with $\mathrm{P}_{2} \mathrm{Y}_{12}$ receptor inhibitors and unfractionated heparin is being used as the primary anticoagulant. ${ }^{63}$ Delayed use (at the time of PCI) is recommended if pretreated with $\mathrm{P} 2 \mathrm{Y}_{12}$ receptor inhibitor. However, if bivalirudin is being used as the primary anticoagulant during PCI, routine use of eptifibatide is not recommended but may be considered if there are angiographic complications. In patients with unstable angina/NSTEMI and stable

Table 4 American College of Cardiology/American Heart Association guidelines (modified) for use of eptifibatide in patients undergoing $\mathrm{PCl}$

\section{STEMI}

Class $\mathrm{Ila}^{\mathrm{a}} \quad$ It is reasonable to begin treatment with double-bolus eptifibatide ${ }^{d}$ at the time of primary $\mathrm{PCl}$ (with or without stenting or clopidogrel pretreatment) in selected patients with STEMI who are receiving UFH.

Class IIb It may be reasonable to administer eptifibatide in the precatheterization laboratory setting (eg, ambulance, ED) to patients with STEMI for whom primary $\mathrm{PCl}$ is intended. $^{\text {D }}$

\section{UA/NSTEMI}

Class $I^{c} \quad$ In UA/STEMI patients with high-risk features (eg, elevated troponin level) not treated with bivalirudin and not adequately pretreated with clopidogrel, it is useful at the time of $\mathrm{PCl}$ to administer eptifibatide in patients treated with UFH. ${ }^{e}$

Class Ila $^{a} \quad$ In high-risk patients treated with UFH and adequately pretreated with clopidogrel, it is reasonable at the time of $\mathrm{PCl}$ to administer eptifibatide. ${ }^{d}$

Class III: No Eptifibatide should not be administered to patients in benefit whom $\mathrm{PCl}$ is not planned.

Stable CAD

Class Ila ${ }^{\mathrm{a}} \quad$ In patients undergoing elective $\mathrm{PCl}$ treated with UFH and not pretreated with clopidogrel, it is reasonable to administer eptifibatide. ${ }^{d}$

Class II $\mathrm{b}^{\mathrm{b}} \quad$ In patients undergoing elective $\mathrm{PCl}$ with stent implantation treated with UFH and adequately pretreated with clopidogrel, it might be reasonable to use eptifibatide. ${ }^{d}$

Notes: ${ }^{a}$ Recommendation that procedure or treatment is useful/effective; brecommendation in favor of treatment or procedure being useful/effective; 'recommendation's usefulness/efficacy less well established; ddata derived from a single randomized trial or nonrandomized studies; 'data derived from multiple randomized clinical trials or meta-analysis.

Abbreviations: $\mathrm{PCl}$, percutaneous coronary intervention; STEMI, ST-segment elevation myocardial infarction; UFH, unfractionated heparin; ED, emergency department; UA, unstable angina; NSTEMI, non ST-segment elevation myocardial infarction; CAD, coronary artery disease. 
coronary artery disease undergoing PCI, the data suggest a benefit of deferred (at the time of PCI) use of eptifibatide in high-risk NSTEMI patients who are not being treated with bivalirudin for anticoagulation; however, the bleeding risk needs to be considered. If bivalirudin is being used at the time of PCI and at least $300 \mathrm{mg}$ of clopidogrel is given at least 6 hours prior to PCI, routine use of a GP IIb/IIIa inhibitor could be omitted. In patients with unstable angina/ NSTEMI already receiving aspirin and a $\mathrm{P} 2 \mathrm{Y}_{12}$ inhibitor, consider upstream use only in high-risk (elevated troponin levels, diabetes, or significant ST-segment depression) patients selected for an invasive strategy and not otherwise at high risk for bleeding. ${ }^{64}$

Pharmacoeconomics are favorable to eptifibatide when compared with other GP IIb/IIIa inhibitors. However, in the contemporary era of $\mathrm{P} 2 \mathrm{Y}_{12}$ inhibitors and bivalirudin, routine use of eptifibatide is not economically viable, mainly because of the increased costs associated with bleeding complications. The cost-effectiveness of eptifibatide when strategies that decrease the bleeding risk like transradial PCI are used is unknown. Single bolus eptifibatide with a truncated infusion regimen may offset some of the increased costs; however, this needs to be explored in larger trials in the future.

Future studies could focus on finding a sweet spot for the risk-benefit and cost-effectiveness of eptifibatide in patients undergoing PCI. Single bolus plus truncated infusion and preferential use in clopidogrel nonresponders ${ }^{66}$ could be potential therapeutic options. With the advent of newer antiplatelet agents with a rapid onset of action, the role of eptifibatide needs to be defined further. ${ }^{67,68}$

In summary, eptifibatide is a potent, short-acting, intravenous antiplatelet agent with a rapid onset of action. There is good evidence that eptifibatide is an effective adjunct to unfractionated heparin in high-risk patients undergoing PCI, where the benefit would outweigh the risk of bleeding. Eptifibatide has an important but selective role in the era of dual antiplatelet therapy, newer safer anticoagulants, and contemporary PCI.

\section{Disclosure}

The authors report no conflicts of interest in this work.

\section{References}

1. Nordmann AJ, Hengstler P, Leimenstoll BM, Harr T, Young J, Bucher HC. Clinical outcomes of stents versus balloon angioplasty in non-acute coronary artery disease: a meta-analysis of randomized controlled trials. Eur Heart J. 2004;25(1):69-80.

2. van Werkum JW, Heestermans AA, Zomer AC, et al. Predictors of coronary stent thrombosis: the Dutch Stent Thrombosis Registry. J Am Coll Cardiol. 2009;53(16):1399-1409.
3. Gurbel PA, Cummings CC, Bell CR, Alford AB, Meister AF, Serebruany VL. Onset and extent of platelet inhibition by clopidogrel loading in patients undergoing elective coronary stenting: the Plavix Reduction Of New Thrombus Occurrence (PRONTO) trial. Am Heart $J$. 2003;145(2):239-247.

4. Steinhubl SR, Ellis SG, Wolski K, Lincoff AM, Topol EJ. Ticlopidine pretreatment before coronary stenting is associated with sustained decrease in adverse cardiac events: data from the Evaluation of Platelet IIb/IIIa Inhibitor for Stenting (EPISTENT) Trial. Circulation. 2001;103(10):1403-1409.

5. Cutlip DE, Baim DS, Ho KKL, et al. Stent thrombosis in the modern era: a pooled analysis of multicenter coronary stent clinical trials. Circulation. 2001;103(15):1967-1971.

6. Holmes DR Jr, Kereiakes DJ, Garg S, et al. Stent thrombosis. J Am Coll Cardiol. 2010;56(17):1357-1365.

7. Reynolds MR, Rinaldi MJ, Pinto DS, Cohen DJ. Current clinical characteristics and economic impact of subacute stent thrombosis. J Invasive Cardiol. 2002;14(7):364-368.

8. Clark MA, Bakhai A, Lacey MJ, Pelletier EM, Cohen DJ. Clinical and economic outcomes of percutaneous coronary interventions in the elderly: an analysis of medicare claims data. Circulation. 2004;110(3): 259-264.

9. McKee SA, Sane DC, Deliargyris EN. Aspirin resistance in cardiovascular disease: a review of prevalence, mechanisms, and clinical significance. Thromb Haemost. 2002;88(5):711-715.

10. Starnes HB, Patel AA, Stouffer GA. Optimal use of platelet glycoprotein $\mathrm{IIb} / \mathrm{III}$ a receptor antagonists in patients undergoing percutaneous coronary interventions. Drugs. 2011;71(15):2009-2030.

11. Kristensen SD, Wurtz M, GroveEL, et al. Contemporary use of glycoprotein IIb/IIIa inhibitors. Thromb Haemost. 2012;107(2):215-224.

12. Scarborough RM, Naughton MA, Teng W, et al. Design of potent and specific integrin antagonists. Peptide antagonists with high specificity for glycoprotein IIb-IIIa. J Biol Chem. 1993;268(2):1066-1073.

13. Tam SH, Sassoli PM, Jordan RE, Nakada MT. Abciximab (ReoPro, chimeric 7E3 Fab) demonstrates equivalent affinity and functional blockade of glycoprotein IIb/IIIa and alpha(v)beta3 integrins. Circulation. 1998;98(11):1085-1091.

14. Kereiakes DJ, Runyon JP, Broderick TM, Shimshak TM. IIb's are not IIb's. Am J Cardiol. 2000;85(8A):23C-31C.

15. Harrington RA, Kleiman NS, Kottke-Marchant K, et al. Immediate and reversible platelet inhibition after intravenous administration of a peptide glycoprotein IIb/IIIa inhibitor during percutaneous coronary intervention. Am J Cardiol. 1995;76(17):1222-1227.

16. [No authors listed]. Randomised placebo-controlled trial of effect of eptifibatide on complications of percutaneous coronary intervention: IMPACT-II. Integrilin to Minimise Platelet Aggregation and Coronary Thrombosis-II. Lancet. 1997;349(9063):1422-1428.

17. Marciniak SJ Jr, Jordan RE, Mascelli MA. Effect of Ca2+ chelation on the platelet inhibitory ability of the GPIIb/IIIa antagonists abciximab, eptifibatide and tirofiban. Thromb Haemost. 2001;85(3):539-543.

18. Kereiakes DJ, Lorenz T, Young JJ, et al. Differential effects of citrate versus PPACK anticoagulation on measured platelet inhibition by abciximab, eptifibatide and tirofiban. J Thromb Thrombolysis. 2001;12(2): 123-127.

19. Tcheng JE, Talley JD, O'Shea JC, et al. Clinical pharmacology of higher dose eptifibatide in percutaneous coronary intervention (the PRIDE study). Am J Cardiol. 2001;88(10):1097-1102.

20. Zeymer U, Zahn R, Schiele R, et al. Early eptifibatide improves TIMI 3 patency before primary percutaneous coronary intervention for acute ST elevation myocardial infarction: results of the randomized integrilin in acute myocardial infarction (INTAMI) pilot trial. Eur Heart $J$. 2005;26(19):1971-1977.

21. Gibson CM, Kirtane AJ, Murphy SA, et al. Early initiation of eptifibatide in the emergency department before primary percutaneous coronary intervention for ST-segment elevation myocardial infarction: results of the Time to Integrilin Therapy in Acute Myocardial Infarction (TITAN)TIMI 34 trial. Am Heart J. 2006;152(4):668-675. 
22. Le May MR, Wells GA, Glover CA, et al. Primary percutaneous coronary angioplasty with and without eptifibatide in ST-segment elevation myocardial infarction: a safety and efficacy study of integrilinfacilitated versus primary percutaneous coronary intervention in STsegment elevation myocardial infarction (ASSIST). Circ Cardiovasc Interv. 2009;2(4):330-338.

23. Stone GW, Witzenbichler B, Guagliumi G, et al. Bivalirudin during primary PCI in acute myocardial infarction. $N$ Engl $\mathrm{J} \mathrm{Med}$. 2008;358(21):2218-2230.

24. Mehran R, Lansky AJ, Witzenbichler B, et al. Bivalirudin in patients undergoing primary angioplasty for acute myocardial infarction (HORIZONS-AMI): 1-year results of a randomised controlled trial. Lancet. 2009;374(9696):1149-1159.

25. [No authors listed]. Inhibition of platelet glycoprotein IIb/IIIa with eptifibatide in patients with acute coronary syndromes. The PURSUIT Trial Investigators. Platelet Glycoprotein IIb/IIIa in Unstable Angina: Receptor Suppression Using Integrilin Therapy. $N$ Engl J Med. 1998;339(7):436-443.

26. Kleiman NS, LincoffAM, Flaker GC, et al. Early percutaneous coronary intervention, platelet inhibition with eptifibatide, and clinical outcomes in patients with acute coronary syndromes. Circulation. 2000;101(7): 751-757.

27. [No authors listed]. Novel dosing regimen of eptifibatide in planned coronary stent implantation (ESPRIT): a randomised, placebocontrolled trial. Lancet. 2000;356(9247):2037-2044.

28. Puma JA, Banko LT, Pieper KS, et al. Clinical characteristics predict benefits from eptifibatide therapy during coronary stenting: insights from the Enhanced Suppression of the Platelet IIb/IIIa Receptor With Integrilin Therapy (ESPRIT) trial. J Am Coll Cardiol. 2006;47(4) 715-718.

29. Stone GW, White HD, Ohman EM, et al. Bivalirudin in patients with acute coronary syndromes undergoing percutaneous coronary intervention: a subgroup analysis from the Acute Catheterization and Urgent Intervention Triage strategy (ACUITY) trial. Lancet. 2007;369(9565):907-919.

30. Lincoff AM, Bittl JA, Harrington RA, et al. Bivalirudin and provisional glycoprotein IIb/IIIa blockade compared with heparin and planned glycoprotein IIb/IIIa blockade during percutaneous coronary intervention: REPLACE-2 randomized trial. JAMA. 2003;289(7):853-863.

31. Gibson CM, Morrow DA, Murphy SA, et al. A randomized trial to evaluate the relative protection against post-percutaneous coronary intervention microvascular dysfunction, ischemia, and inflammation among antiplatelet and antithrombotic agents: the PROTECT-TIMI-30 trial. J Am Coll Cardiol. 2006;47(12):2364-2373.

32. Zeymer U, Margenet A, Haude M, et al. Randomized comparison of eptifibatide versus abciximab in primary percutaneous coronary intervention in patients with acute ST-segment elevation myocardial infarction: results of the EVA-AMI Trial. J Am Coll Cardiol. 2010;56(6):463-469.

33. Akerblom A, James SK, Koutouzis M, et al. Eptifibatide is noninferior to abciximab in primary percutaneous coronary intervention: results from the SCAAR (Swedish Coronary Angiography and Angioplasty Registry). J Am Coll Cardiol. 2010;56(6):470-475.

34. Singh HS, Dangas GD, Guagliumi G, et al. Comparison of abciximab versus eptifibatide during percutaneous coronary intervention in STsegment elevation myocardial infarction (from the HORIZONS-AMI trial). Am J Cardiol. 2012;110(7):940-947.

35. Lopes RD, Alexander KP, Manoukian SV, et al. Advanced age, antithrombotic strategy, and bleeding in non-ST-segment elevation acute coronary syndromes: results from the ACUITY (Acute Catheterization and Urgent Intervention Triage Strategy) trial. $J \mathrm{Am}$ Coll Cardiol. 2009;53(12):1021-1030.

36. Alexander KP, Chen AY, Newby LK, et al. Sex differences in major bleeding with glycoprotein IIb/IIIa inhibitors: results from the CRUSADE (Can Rapid risk stratification of Unstable angina patients Suppress Adverse outcomes with Early implementation of the ACC/ AHA guidelines) initiative. Circulation. 2006;114(13):1380-1387.
37. Alexander KP, Chen AY, Roe MT, et al. Excess dosing of antiplatelet and antithrombin agents in the treatment of non-ST-segment elevation acute coronary syndromes. JAMA. 2005;294(24):3108-3116.

38. Fung AY, Saw J, Starovoytov A, et al. Abbreviated infusion of eptifibatide after successful coronary intervention the BRIEF-PCI (Brief Infusion of Eptifibatide Following Percutaneous Coronary Intervention) randomized trial. J Am Coll Cardiol. 2009;53(10):837-845.

39. Kini AS, Chen VH, Krishnan P, et al. Bolus-only versus bolus + infusion of glycoprotein IIb/IIIa inhibitors during percutaneous coronary intervention. Am Heart J. 2008;156(3):513-519.

40. Dalby M, Montalescot G, Bal dit Sollier C, et al. Eptifibatide provides additional platelet inhibition in non-ST-elevation myocardial infarction patients already treated with aspirin and clopidogrel. Results of the platelet activity extinction in non-Q-wave myocardial infarction with aspirin, clopidogrel, and eptifibatide (PEACE) study. J Am Coll Cardiol. 2004;43(2):162-168.

41. Gurbel PA, Bliden KP, Zaman KA, Yoho JA, Hayes KM, Tantry US. Clopidogrel loading with eptifibatide to arrest the reactivity of platelets: results of the Clopidogrel Loading With Eptifibatide to Arrest the Reactivity of Platelets (CLEAR PLATELETS) study. Circulation. 2005;111(9):1153-1159.

42. Giugliano RP, White JA, Bode C, et al. Early versus delayed, provisional eptifibatide in acute coronary syndromes. NEngl J Med. 2009;360(21): 2176-2190.

43. Stone GW, Bertrand ME, Moses JW, et al. Routine upstream initiation vs deferred selective use of glycoprotein IIb/IIIa inhibitors in acute coronary syndromes: the ACUITY Timing trial. JAMA. 2007;297(6): 591-602.

44. Hamon M, Rasmussen LH, Manoukian SV, et al. Choice of arterial access site and outcomes in patients with acute coronary syndromes managed with an early invasive strategy: the ACUITY trial. EuroIntervention. 2009;5(1):115-120.

45. Moody WE, Chue CD, Ludman PF, et al. Bleeding outcomes after routine transradial primary angioplasty for acute myocardial infarction using eptifibatide and unfractionated heparin: a single-center experience following the HORIZONS-AMI trial. Catheter Cardiovasc Interv. 2013;82(3):E138-E147.

46. Eichhofer J, Horlick E, Ivanov J, et al. Decreased complication rates using the transradial compared to the transfemoral approach in percutaneous coronary intervention in the era of routine stenting and glycoprotein platelet IIb/IIIa inhibitor use: a large single-center experience. Am Heart J. 2008;156(5):864-870.

47. Mark DB, Harrington RA, Lincoff AM, et al. Cost-effectiveness of platelet glycoprotein IIb/IIIa inhibition with eptifibatide in patients with non-ST-elevation acute coronary syndromes. Circulation. 2000;101(4): 366-371.

48. Plosker GL, Ibbotson T. Eptifibatide: a pharmacoeconomic review of its use in percutaneous coronary intervention and acute coronary syndromes. Pharmacoeconomics. 2003;21(12):885-912.

49. Dewilde S, Bruggenjurgen B, Nienaber C, Senges J, Welte R, Willich SN. Cost-effectiveness of adjunctive eptifibatide in patients undergoing coronary stenting in Germany. Eur J Health Econ. 2012;13(4): 381-391.

50. PRICE Investigators. Comparative 30-day economic and clinical outcomes of platelet glycoprotein IIb/IIIa inhibitor use during elective percutaneous coronary intervention: Prairie ReoPro versus Integrilin Cost Evaluation (PRICE) Trial. Am Heart J. 2001;141(3): 402-409.

51. Coons JC, Seybert AL, Saul MI, Kirisci L, Kane-Gill SL. Outcomes and costs of abciximab versus eptifibatide for percutaneous coronary intervention. Ann Pharmacother. 2005;39(10):1621-1626.

52. Le Pen C, Lilliu H. Choice of GPIIb/IIIa antagonist in percutaneous coronary intervention: how should economic criteria be factored in? Pharm World Sci. 2005;27(2):83-91.

53. Cantor WJ, Fitchett D, Borgundvaag B, et al. Routine early angioplasty after fibrinolysis for acute myocardial infarction. $N \mathrm{Engl} \mathrm{J} \mathrm{Med.}$ 2009;360(26):2705-2718. 
54. Bagai A, Cantor WJ, Tan M, et al. Clinical outcomes and cost implications of routine early PCI after fibrinolysis: one-year follow-up of the Trial of Routine Angioplasty and Stenting after Fibrinolysis to Enhance Reperfusion in Acute Myocardial Infarction (TRANSFERAMI) study. Am Heart J. 2013;165(4):630-637. e632.

55. Cohen DJ, Lincoff AM, Lavelle TA, et al. Economic evaluation of bivalirudin with provisional glycoprotein IIB/IIIA inhibition versus heparin with routine glycoprotein IIB/IIIA inhibition for percutaneous coronary intervention: results from the REPLACE-2 trial. J Am Coll Cardiol. 2004;44(9):1792-1800.

56. Summers KM, Holdford DA, Crouch MA. Cost-effectiveness analysis of antithrombotic therapy in nonurgent percutaneous coronary intervention. Pharmacotherapy. 2006;26(5):609-618.

57. Pinto DS, Stone GW, Shi C, et al. Economic evaluation of bivalirudin with or without glycoprotein IIb/IIIa inhibition versus heparin with routine glycoprotein IIb/IIIa inhibition for early invasive management of acute coronary syndromes. J Am Coll Cardiol. 2008;52(22):1758-1768.

58. Amin AP, Magnuson EA. Understanding the cost-effectiveness of bivalirudin. Heart. 2012;98(14):1037-1039.

59. Schwenkglenks M, Toward TJ, Plent S, Szucs TD, Blackman DJ, Baumbach A. Cost-effectiveness of bivalirudin versus heparin plus glycoprotein IIb/IIIa inhibitor in the treatment of acute ST-segment elevation myocardial infarction. Heart. 2012;98(7):544-551.

60. Fischell TA, Attia T, Rane S, Salman W. High-dose, single-bolus eptifibatide: a safe and cost-effective alternative to conventional glycoprotein IIb/IIIa inhibitor use for elective coronary interventions. J Invasive Cardiol. 2006;18(10):487-491.

61. Helmy T, Effat M. Commentary: alternative safe, effective and costefficient dosing for eptifibatide in low-risk patients. J Invasive Cardiol. 2006;18(10):492-493.
62. Yusuf S, Zhao F, Mehta SR, Chrolavicius S, Tognoni G, Fox KK. Effects of clopidogrel in addition to aspirin in patients with acute coronary syndromes without ST-segment elevation. N Engl J Med. 2001;345(7): 494-502.

63. O'Gara PT, Kushner FG, Ascheim DD, et al. 2013 ACCF/AHA guideline for the management of ST-elevation myocardial infarction: a report of the American College of Cardiology Foundation/American Heart Association Task Force on Practice Guidelines. J Am Coll Cardiol. 2013;61(4):e78-e140.

64. Wright RS, Anderson JL, Adams CD, et al. 2011 ACCF/AHA focused update of the Guidelines for the Management of Patients With Unstable Angina/Non-ST-Elevation Myocardial Infarction (updating the 2007 guideline): a report of the American College of Cardiology Foundation/ American Heart Association Task Force on Practice Guidelines. J Am Coll Cardiol. 2011;57(19):1920-1959.

65. Levine GN, Bates ER, Blankenship JC, et al. 2011 ACCF/AHA/SCAI Guideline for Percutaneous Coronary Intervention: a report of the American College of Cardiology Foundation/American Heart Association Task Force on Practice Guidelines and the Society for Cardiovascular Angiography and Interventions. Circulation. 2012;125(8):e412.

66. Cuisset T, Frere C, Quilici J, et al. Glycoprotein IIb/IIIa inhibitors improve outcome after coronary stenting in clopidogrel nonresponders. a prospective, randomized study. JACC Cardiovasc Interv. 2008;1(6): 649-653.

67. Wallentin L, Becker RC, Budaj A, et al. Ticagrelor versus clopidogrel in patients with acute coronary syndromes. N Engl J Med. 2009;361(11): 1045-1057.

68. Bhatt DL, Lincoff AM, Gibson CM, et al. Intravenous platelet blockade with cangrelor during PCI. N Engl J Med. 2009;361(24):2330-2341.
Therapeutics and Clinical Risk Management

\section{Publish your work in this journal}

Therapeutics and Clinical Risk Management is an international, peerreviewed journal of clinical therapeutics and risk management, focusing on concise rapid reporting of clinical studies in all therapeutic areas outcomes, safety, and programs for the effective, safe, and sustained use of medicines. This journal is indexed on PubMed Central, CAS,

\section{Dovepress}

EMBase, Scopus and the Elsevier Bibliographic databases. The manuscript management system is completely online and includes a very quick and fair peer-review system, which is all easy to use. Visit http://www.dovepress.com/testimonials.php to read real quotes from published authors. 